\title{
Attitudes towards offensive advertising: Malaysian Muslims' views
}

\author{
Ernest Cyril De Run and Muhammad Mohsin Butt \\ Faculty of Economics and Business, University Malaysia Sarawak, \\ Kota Samarahan, Malaysia \\ Kim-Shyan Fam \\ School of Marketing, Victoria University of Wellington, Wellington, \\ New Zealand, and$$
\text { Hui Yin Jong }
$$

Faculty of Economics and Business, University Malaysia Sarawak, Kota Samarahan, Malaysia

\begin{abstract}
Purpose - The purpose of this paper is to investigate the Malaysian Malays attitude towards offensive advertising and the reasons that make these advertisements offensive. This paper aims to explore the role of religiosity on attitudes towards controversial advertisements and the reasons why they are controversial.

Design/methodology/approach - This paper consists of 279 randomly selected Malay participants. Data were analyzed using means, correlations, and ANOVA.

Findings - Results indicate that those high on religiosity differ on the nature and manner of controversial advertisements from those of low religiosity. Malay Muslims when compared on their degree of religiosity differ in terms of their evaluation of offensive nature of advertisement. More important they differ more on the reason that make these advertisement offensive compared to the nature of the products.
\end{abstract}

Research limitations/implications - Respondents are somewhat more skewed towards a younger population causing concern that the results might not be a true indication of all Malaysian age groups. Originality/value - The original value of the research lies in its effort to examine the results from the lens of religious theology and respondent degree of religiosity.

Keywords Advertising, Advertising effectiveness, Public opinion, Religion, Islam, Malaysia

Paper type Research paper

\section{Introduction}

It is an established fact that religion plays a significant role in human behavior and attitudes (Armstrong, 2001; Arnould et al., 2004). Religion affects our goals, motivation and satisfaction by influencing how we live and experience life (Ellison and Cole, 1982). However, a universal application that religion dominates human attitude towards life is not appropriate. First and foremost it is the degree of religious affiliation that dictates the influence of religion on individual's attitude and subsequent behavior. Second, religions have different degrees of social impact on different societies. Third, different religions have different degrees of influence on the social fabric of a society. For example, how religion affects food consumption differs across religions. Fourth, religions differ in their emphasis on values and vices. 